\title{
Systemic Inflammation Mediates the Associations Between Abdominal Obesity Indices and Lung Function Decline in a Chinese General Population
}

This article was published in the following Dove Press journal: Diabetes, Metabolic Syndrome and Obesity: Targets and Therapy

\author{
Heng $\mathrm{He}^{1,2}$ \\ Bin Wang ${ }^{1,2}$ \\ Min Zhou ${ }^{1,2}$ \\ Limin Cao ${ }^{1,2}$ \\ Weihong Qiu (D) ${ }^{1,2}$ \\ Ge Mu ${ }^{1,2}$ \\ Ailian Chen ${ }^{1,2}$ \\ Shijie Yang ${ }^{1,2}$ \\ Weihong Chen ${ }^{1,2}$ \\ 'Department of Occupational \& \\ Environmental Health, School of Public \\ Health, Tongji Medical College, Huazhong \\ University of Science and Technology, \\ Wuhan, Hubei 430030, People's Republic \\ of China; ${ }^{2}$ Key Laboratory of \\ Environment and Health, Ministry of \\ Education \& Ministry of Environmental \\ Protection, and State Key Laboratory of \\ Environmental Health (Incubating), \\ School of Public Health, Tongji Medical \\ College, Huazhong University of Science \\ and Technology, Wuhan, Hubei 430030, \\ People's Republic of China
}

Correspondence: Weihong Chen Department of Occupational and Environmental Health, School of Public Health, Tongji Medical College, Huazhong University of Science and Technology, Wuhan, Hubei 430030, People's Republic of China

Tel +86278369l677

Email wchen@mails.tjmu.edu.cn
Background: Previous studies reported that obesity indices were inversely associated with lung function. However, the underlying mechanisms remain unclear. We aimed to assess the potential mediating effect of systemic inflammation in the associations between obesity indices and lung function decline among a general population.

Methods: We conducted a cross-sectional study among 3442 participants from the WuhanZhuhai cohort. Plasma C-reactive protein (CRP) was assayed as a marker of systemic inflammation. The relationships among several obesity indices (body mass index, BMI; waist circumference, WC; waist-to-hip ratio, WHR; waist-to-height ratio, WHtR), plasma CRP and lung function were assessed by generalized linear models. The role of CRP in the associations between obesity indices and lung function was analyzed using mediation analysis.

Results: We observed inverse associations between abdominal obesity indices (WC, WHR and WHtR) and lung function parameters, including forced expiratory volume in $1 \mathrm{~s}\left(\mathrm{FEV}_{1}\right)$ and forced vital capacity $(\mathrm{FVC})($ all $P<0.05)$. Each 1 -unit increase in WC was associated with a $3.39 \mathrm{~mL}$ decrease in $\mathrm{FEV}_{1}$ and a $3.96 \mathrm{~mL}$ decrease in FVC (all $P<0.05$ ). Each $1 \%$ increase in WHR and WHtR was associated with a $5.42 \mathrm{~mL}$ and a $14.23 \mathrm{~mL}$ decrease in $\mathrm{FEV}_{1}$, and a $5.70 \mathrm{~mL}$ and a $16.92 \mathrm{~mL}$ decrease in FVC (all $P<0.05$ ). Mediation analysis indicated that plasma CRP partly mediated the associations between abdominal obesity and lung function. The mediated proportions of CRP in associations of WC, WHR and WHtR with $\mathrm{FEV}_{1}$ were $7.96 \%, 9.59 \%$ and $5.76 \%$, respectively. The mediated proportions of CRP in associations of WC and WHR with FVC were $8.33 \%$ and $11.40 \%$, respectively.

Conclusion: Abdominal obesity indices were negatively associated with lung function, and the associations may be partly mediated by systemic inflammation.

Keywords: abdominal obesity, systemic inflammation, lung function, mediation analysis

\section{Background}

In 2016, more than 1.95 billion adults worldwide were overweight, and among them over 671 million were obese. ${ }^{1}$ As a global pandemic, obesity has been demonstrated to reduce the life expectancy and lead to a heavy disease burden. ${ }^{2}$ Obesity has long been considered as a risk factor for many chronic diseases including respiratory diseases, ${ }^{3,4}$ cardiovascular diseases, ${ }^{5-7}$ type 2 diabetes ${ }^{8-10}$ and liver diseases. ${ }^{11,12}$ Impaired lung function is an indicator of early respiratory injury and a crucial clinical parameter in the diagnosis of airway dysfunction. Current publications have suggested that obesity, especially abdominal obesity, 
was associated with impaired lung function. ${ }^{13-15}$ However, the underlying mechanisms whereby obesity affects the lung function remain unclear.

Systemic inflammation has been reported to be involved in the process of obesity-induced damage and might play a role in the pathogenesis of lung function decline. ${ }^{16,17} \mathrm{C}$-reactive protein (CRP) is a sensitive marker of low-grade systemic inflammation and a common index in clinical practice. Increasing evidences suggest that some features of metabolic abnormalities such as obesity are risk factors of elevated CRP levels. ${ }^{18,19}$ On the other hand, systemic inflammation marker CRP has been reported to directly induce lung function decline. One in vitro study showed that CRP existed in the secretions of human respiratory tract, ${ }^{20}$ and this protein may exert local effects in lung tissue, leading to a subtle reduction in airway diameter and a reduction in lung function. Therefore, we hypothesized that systemic inflammation might mediate and play a part in the associations between obesity indices and declined lung function.

In the present study, we measured the levels of four obesity indices (body mass index, BMI; waist circumference, WC; waist-to-hip ratio, WHR; waist-to-height ratio, WHtR), plasma CRP and lung function in 3442 adults from the Wuhan-Zhuhai cohort in China. The main objectives of this study are: 1) to analyze the associations among obesity indices, plasma CRP and lung function; 2) to assess the mediating role of systemic inflammation presented by plasma CRP in the associations between obesity indices and declined lung function.

\section{Methods}

\section{Study Design and Population}

The study participants were originated from the baseline survey of Wuhan-Zhuhai cohort, which has been described previously. ${ }^{24}$ Briefly, this community-based prospective cohort was established between 2011 and 2012, including 4812 individuals aged 18-80 years who had lived in Wuhan or Zhuhai city for more than 5 years. Each participant underwent standardized questionnaires and physical examination on the same day. We excluded 1370 participants who had physician-diagnosed respiratory diseases, or who failed to conduct anthropometry, lung function or plasma CRP. A total of 3442 subjects were ultimately included. Individuals included and excluded in our study showed no differences with respect to basic demographic characteristics such as body mass index, smoking status, drinking status, education levels, etc. $(P>0.05)$. All participants in the study signed written informed consent. The study was approved by the Ethics and Human Subject Committee of Tongji Medical College, Huazhong University of Science and Technology (No. 2011-17).

\section{Anthropometry}

Standing height $(\mathrm{cm})$ and body weight $(\mathrm{kg})$ were measured in light clothing and no shoes, using the weighing scale with a vertically fixed ruler (RGZ-120, China). BMI was calculated as the weight in kilograms divided by the square of the height in meters. WC was measured midway between the lower costal margin and the iliac crest using a horizontally placed tape, and hip circumference at the maximum circumference of the buttocks. WHR was calculated as the WC in centimeters divided by the hip circumference in centimeters, while WHtR was calculated as the WC in centimeters divided by the height in centimeters. Abdominal obesity was defined as follows: WC $\geq 90 \mathrm{~cm}$ in men and $\geq 85 \mathrm{~cm}$ in women. ${ }^{25}$

\section{Lung Function Test}

Lung function tests including forced expiratory volume in $1 \mathrm{~s}\left(\mathrm{FEV}_{1}\right)$, forced vital capacity $(\mathrm{FVC})$ and the ratio of $\mathrm{FEV}_{1}$ to $\mathrm{FVC}\left(\mathrm{FEV}_{1} / \mathrm{FVC}\right)$ were performed with a digital spirometer (Chestgraph HI-101, CHEST MI, Inc., Tokyo, Japan), based on the American Thoracic Society Recommendations. ${ }^{26}$ The spirometry devices were calibrated each morning before testing, according to the manufacturer's instruction. Each participant was required to keep a sitting position, wear a nose clip and breathe through the blowing nozzle. Three satisfactory volumetime curves were performed for each participant, and the highest value of $\mathrm{FEV}_{1}$ or $\mathrm{FVC}$ was used in the analyses.

\section{Plasma CRP Measurements}

Venous blood sample was collected from each participant after a 12-h fast at baseline examination and kept frozen at $-80^{\circ} \mathrm{C}$ until being thawed for CRP analysis. Plasma CRP was determined with a commercially available enzymelinked immunosorbent assay (ELISA) kit (R\&D Systems, MN, USA) according to manufacturer's instructions, with the range of $15.6-1000 \mathrm{pg} / \mathrm{mL}$. All the samples were replicated two times.

\section{Definitions of Covariates}

Information on sociodemographic characteristics (gender, age, city, and family income), occupational hazard 
exposure (industrial dust, noise, tobacco smoking, cooking or heating in the winter), lifestyles (smoking status, drinking status, regular physical activity and cooking meals at home), drug status and chronic diseases history was collected through questionnaires by face-to-face interviews with trained interviewers. Individuals who had been smoking at least one cigarette per day for more than half a year were defined as current smokers, and those who had been drinking alcohol at least one time per week for more than half a year were defined as current drinkers. Smoking status was assessed as smokers (current and former smokers) and nonsmokers. Drinking status was assessed as drinkers (current and former drinkers) and nondrinkers. Regular physical activity was defined as regular exercise at least twice a week for more than 20 min each time over the last 6 months. Drug status was assessed by asking "Did you take any medication (antilipemic agent, antihypertensive drug, oral antidiabetic agents, insulin, paregoric, aspirin, antibiotic, asthma drugs and so on) over the past 2 weeks".

\section{Statistical Analysis}

For continuous analyses, plasma CRP was log-transformed due to its right-skewed distribution. For categorical analyses, participants were divided into four groups according to the quartiles of CRP levels. The baseline characteristics of the groups were compared using analysis of variance for continuous variables and using Chi-square test for categorical variables.

Both continuous and categorical analyses were conducted to quantify the associations among obesity indices, CRP concentration and lung function parameters $\left(\mathrm{FEV}_{1}\right.$, $\mathrm{FVC}$ and $\mathrm{FEV}_{1} / \mathrm{FVC}$ ) by generalized linear models with adjustment for potential confounders, including gender, age, city, occupational hazard exposure, drug status, smoking status, drinking status, regular physical activity, cooking meals at home, and family income. Stratified analyses were conducted to investigate whether gender and smoking status modified the associations among obesity indices, plasma CRP and lung function in separate generalized linear models, without adjusting for the stratification variable. Effect modification was tested by including an interaction term of obesity indices or plasma CRP multiplied by gender or smoking status in the generalized linear models. We further divided smokers into groups of nonabdominal obesity and abdominal obesity, the associations between obesity indices and lung function were analyzed by generalized linear model in each subgroup.
To assess the mediating role of CRP in the associations between obesity indices and lung function, we conducted mediation analyses by using MEDIATION macro described by Valeri L and VanderWeele $\mathrm{T} \mathrm{J.}{ }^{27}$ We first assessed the joint effect of obesity indices and plasma CRP on lung function by including an interaction term of obesity indices multiplied by plasma CRP in the generalized linear models. If there was no joint effect, we then ran the mediation macro with the correctly specified outcome regression model without the exposure-mediator interaction term. If there is a joint effect, we included the exposure-mediator interaction term into the model. We also calculated the proportion mediated as follows: Proportion mediated $=$ Mediated effect $/$ Total effect $\times 100 \%$. All tests were two-sided with a significant level at 0.05, and all statistical analyses were conducted using SAS 9.4 software (SAS Institute Inc., Cary, NC, USA).

\section{Results}

\section{Basic Characteristics}

The characteristics of the 3442 subjects according to the quartiles of plasma CRP are displayed in Table 1. The mean age of all participants (1087 men; 31.58\%) was 52.77 (12.76) years. The median, lower and upper quartile of plasma CRP concentration were estimated at 0.581 and (0.226 to 1.381$) \mathrm{mg} / \mathrm{l}$. Participants with higher plasma CRP levels tended to be older and smokers, had a higher BMI, WC, WHR and WHtR, had lower FEV 1 and FVC, were less likely to be physically active and were more likely to cooking meals at home.

\section{Associations Between Obesity Indices and Lung Function Alteration}

The associations between obesity indices and lung function alteration are presented in Table 2 . After adjusting for potential confounders, abdominal obesity indices including $\mathrm{WC}$, WHR, and WHtR were negatively associated with $\mathrm{FEV}_{1}$ and FVC. In the continuous analyses, each 1-unit increase in WC was associated with a $3.39 \mathrm{~mL}$ decrease in $\mathrm{FEV}_{1}$ and a $3.96 \mathrm{~mL}$ decrease in FVC (all $P<0.05$ ). Each $1 \%$ increase in WHR and WHtR was associated with a $5.42 \mathrm{~mL}$ and a $14.23 \mathrm{~mL}$ decrease in $\mathrm{FEV}_{1}$, and a $5.70 \mathrm{~mL}$ and a $16.92 \mathrm{~mL}$ decrease in $\mathrm{FVC}$, respectively (all $P<0.05$ ). No significant association was observed between BMI and $\mathrm{FEV}_{1}$ or FVC. In the categorical analyses, we found significantly monotonic $\mathrm{FEV}_{1}$ and $\mathrm{FVC}$ declines with gradually increasing WC, WHR or WHtR (all $P$ for trend $<0.05$ ). While, FEV 1 
Table I Basic Characteristics of Participants by Quartile of Plasma CRP Levels ( $N=3442)$

\begin{tabular}{|c|c|c|c|c|c|c|}
\hline \multirow[t]{2}{*}{ Characteristics } & \multirow{2}{*}{$\begin{array}{l}\text { All } \\
\text { Participants }\end{array}$} & \multicolumn{4}{|c|}{ Quartile of Plasma CRP Level, mg/l } & \multirow[t]{2}{*}{$P$ value } \\
\hline & & $\leq 0.226$ & $0.226-0.58 I$ & $0.58 I-I .38 I$ & $>1.38 \mathrm{I}$ & \\
\hline No. of participant & 3442 & 860 & 861 & 860 & 861 & \\
\hline Male, n (\%) & $1087(31.58)$ & $270(31.40)$ & $264(30.66)$ & $285(33.14)$ & $268(31.13)$ & 0.8138 \\
\hline Age, years (mean $\pm S D$ ) & $52.77 \pm 12.76$ & $48.12 \pm 13.54$ & $52.16 \pm 12.13$ & $54.87 \pm 12.36$ & $55.92 \pm|1.5|$ & $<0.0001$ \\
\hline Family income $\geq 40,000$ RMB/year, n (\%) & $|45|(42.16)$ & $381(44.30)$ & $358(41.58)$ & $379(44.07)$ & $333(38.68)$ & 0.0559 \\
\hline Regular physical activity, n (\%) & $1808(42.16)$ & $486(56.5 \mathrm{I})$ & $460(53.43)$ & $432(50.23)$ & $430(49.94)$ & 0.0062 \\
\hline Cooking meals at home, $\mathrm{n}(\%)$ & $2547(74.00)$ & $613(71.28)$ & $632(73.40)$ & $638(74.19)$ & $664(77.12)$ & 0.0062 \\
\hline Occupational hazard expose/yes, $\mathrm{n}(\%)$ & $1024(29.75)$ & $243(28.26)$ & $26 I(30.3 I)$ & $253(29.42)$ & $267(31.01)$ & 0.6252 \\
\hline Drug status/yes, n (\%) & $1513(43.96)$ & $31436.5 I)$ & $345(40.07)$ & $409(47.56)$ & $445(51.68)$ & $<0.0001$ \\
\hline $\begin{array}{l}\text { Smoking status } \\
\text { Smokers } \\
\text { Nonsmokers }\end{array}$ & $\begin{array}{l}724(21.03) \\
2718(78.97)\end{array}$ & $\begin{array}{l}156(18.14) \\
704(81.86)\end{array}$ & $\begin{array}{l}174(20.20) \\
687(79.79)\end{array}$ & $\begin{array}{l}199(23.14) \\
661(78.86)\end{array}$ & $\begin{array}{l}195(22.65) \\
666(77.35)\end{array}$ & 0.0081 \\
\hline $\begin{array}{l}\text { Drinking status } \\
\text { Drinkers } \\
\text { Nondrinkers }\end{array}$ & $\begin{array}{l}579(16.82) \\
2863(83.18)\end{array}$ & $\begin{array}{l}|3|(\mid 5.23) \\
729(84.77)\end{array}$ & $\begin{array}{l}154(17.89) \\
707(82.11)\end{array}$ & $\begin{array}{l}162(18.84) \\
698(81.16)\end{array}$ & $\begin{array}{l}132(15.33) \\
729(84.67)\end{array}$ & 0.1067 \\
\hline BMI, $\mathrm{kg} / \mathrm{m}^{2}($ mean $\pm \mathrm{SD})$ & $24.00 \pm 3.43$ & $22.45 \pm 3.04$ & $23.68 \pm 3.04$ & $24.58 \pm 3.37$ & $25.29 \pm 3.57$ & $<0.0001$ \\
\hline WC, cm (mean $\pm S D)$ & $81.35 \pm 11.59$ & $76.29 \pm 11.69$ & $81.03 \pm 9.51$ & $83.49 \pm 11.13$ & $84.59 \pm 12.08$ & $<0.0001$ \\
\hline WHR (mean \pm SD) & $0.87 \pm 0.07$ & $0.84 \pm 0.06$ & $0.87 \pm 0.07$ & $0.88 \pm 0.07$ & $0.89 \pm 0.06$ & $<0.0001$ \\
\hline $\mathrm{WHtR}($ mean $\pm \mathrm{SD})$ & $0.5 I \pm 0.07$ & $0.48 \pm 0.07$ & $0.5 I \pm 0.06$ & $0.53 \pm 0.07$ & $0.54 \pm 0.08$ & $<0.0001$ \\
\hline $\mathrm{FEV}_{\mathrm{l}}, \mathrm{mL}($ mean $\pm \mathrm{SD})$ & $2179.60 \pm 597.82$ & $23|2.2| \pm 602.8 \mid$ & $2205.11 \pm 606.34$ & $2146.74 \pm 601.43$ & $2054.47 \pm 550.53$ & $<0.0001$ \\
\hline $\mathrm{FVC}, \mathrm{mL}($ mean $\pm \mathrm{SD})$ & $2500.30 \pm 689.98$ & $2631.98 \pm 691.05$ & $2551.10 \pm 691.55$ & $2445.35 \pm 702.34$ & $2372.47 \pm 646.20$ & $<0.0001$ \\
\hline $\mathrm{FEV}_{\mathrm{l}} / \mathrm{FVC}($ mean $\pm \mathrm{SD})$ & $87.63 \pm 8.46$ & $88.44 \pm 8.42$ & $86.93 \pm 8.48$ & $88.09 \pm 8.31$ & $87.04 \pm 8.56$ & 0.0001 \\
\hline
\end{tabular}

Abbreviations: CRP, C-reactive protein; SD, standard deviation; BMI, Body mass index; WC, Waist circumference; WHR, Waist-to-hip ratio; WHtR, Waist-to-height ratio; $\mathrm{FEV}_{1}$, forced expiratory volume in I s; FVC, forced vital capacity.

/FVC was not related to obesity indices in neither continuous analyses nor categorical analyses.

Stratified analyses suggested that gender and smoking status modified the negative associations between obesity indices and lung function. The associations between obesity indices and lung function decline among males, females and non-smokers were consistent with those from the primary analyses. While among smokers, the associations between $\mathrm{WC}$ and $\mathrm{FEV}_{1}$ and the association between WC or WHR and FVC were out of significance (Supplementary Table 1). We further divided the smokers into groups of non-abdominal obesity and abdominal obesity, and the results showed that the obesity indices in the abdominal obesity group led to a larger decline in lung function (Supplementary Table 2).

\section{Associations Between Obesity Indices and CRP Concentration}

The associations between obesity indices and CRP concentration are shown in Table 3. Each 1-unit increase in BMI or WC was associated with 0.048 and 0.005 increase in logtransformed CRP concentration $(P<0.05)$. Each $1 \%$ increase in WHR or WHtR was associated with 0.010 and 0.012 increase in plasma CRP, respectively (all $P<0.05$ ). In the categorical analyses, the CRP concentration was significantly and monotonously increased with increasing quartiles of BMI, WC, WHR and WHtR (all $P$ for trend $<0.05$ ). Stratified analyses showed that the associations between obesity indices and CRP concentration remained stable among males, females, smokers and non-smokers (Supplementary Figure 1). 
Table 2 Association Between Obesity Indices and Lung Function Parameters ( $\mathrm{N}=3442)$

\begin{tabular}{|c|c|c|c|c|c|c|}
\hline \multirow[t]{2}{*}{ Parameter } & \multirow{2}{*}{$\begin{array}{l}\text { Estimated Changes ( } \mathrm{mL}) \\
(95 \% \mathrm{Cl}) \text { by Continuous } \\
\text { Obesity Indices }\end{array}$} & \multicolumn{4}{|c|}{ Estimated Changes in $\mathrm{mL}(95 \% \mathrm{Cl})$ by Obesity Indices } & \multirow{2}{*}{$\begin{array}{l}P \text { value } \\
\text { for } \\
\text { Trend }\end{array}$} \\
\hline & & QI & Q2 & Q3 & Q4 & \\
\hline BMI* & & $\leq 21.63$ & $21.63-23.76$ & $23.76-26.09$ & $>26.09$ & \\
\hline $\mathrm{FEV}_{1}$ & $1.27(-3.03,5.58)$ & 0 (ref) & $|7.2|(-24.11,58.53)$ & $71.07(29.53,112.62)$ & $17.37(-24.32,59.07)$ & 0.1208 \\
\hline FVC & $-1.15(-6.24,3.95)$ & 0 (ref) & $15.30(-33.64,64.23)$ & $57.84(8.64,107.04)$ & $-4.75(-54.13,44.63)$ & 0.7374 \\
\hline $\mathrm{FEV}_{1} / \mathrm{FVC}$ & $0.06(-0.02,0.14)$ & 0 (ref) & $0.20(-0.58,0.98)$ & $0.42(-0.36,1.21)$ & $0.62(-0.16, \mid .41)$ & 0.0991 \\
\hline $\mathrm{WC}^{\dagger}$ & & $\leq 74.90$ & $74.90-81.60$ & $81.60-88.20$ & $>88.20$ & \\
\hline $\mathrm{FEV}_{\mathrm{I}}$ & $-3.39(-5.16,-1.63)$ & 0 (ref) & $14.30(-27.79,56.39)$ & -24.5 I $(-73.28,24.25)$ & $-99.27(-163.39,-35.15)$ & 0.0030 \\
\hline FVC & $-3.96(-6.06,-1.87)$ & 0 (ref) & $8.57(-41.39,58.52)$ & $-23.94(-81.82,33.95)$ & $-114.37(-191.48,-38.25)$ & 0.0058 \\
\hline $\mathrm{FEV}_{1} / \mathrm{FVC}$ & $0.01(-0.03,0.04)$ & 0 (ref) & $-0.10(-0.93,0.74)$ & $0.01(-0.96,0.99)$ & $0.02(-1.26,1.30)$ & 0.9308 \\
\hline WHR*100 ${ }^{\dagger}$ & & $\leq 82.06$ & $82.06-86.77$ & $86.77-91.54$ & $>91.54$ & \\
\hline $\mathrm{FEV}_{1}$ & $-5.42(-8.04,-2.8 I)$ & 0 (ref) & $-35.56(-76.00,4.89)$ & $-41.68(-85.29,1.92)$ & $-107.93(-156.07,-59.80)$ & $<0.0001$ \\
\hline FVC & $-5.70(-8.81,-2.60)$ & 0 (ref) & $-29.24(-77.27,18.78)$ & $-41.95(-93.72,9.83)$ & $-111.01(-168.16,-54.86)$ & 0.0002 \\
\hline $\mathrm{FEV}_{1} / \mathrm{FVC}$ & $-0.01(-0.06,0.05)$ & 0 (ref) & $0.01(-0.80,0.82)$ & $0.06(-0.81,0.92)$ & $-0.07(-1.03,0.89)$ & 0.9158 \\
\hline $\mathrm{WH} \mathrm{tR}^{*} * 100^{\ddagger}$ & & $\leq 47.17$ & $47.17-51.25$ & $51.25-55.52$ & $>55.52$ & \\
\hline $\mathrm{FEV}_{\mathrm{I}}$ & $-14.23(-16.71,-11.75)$ & 0 (ref) & $-77.05(-118.70,-35.39)$ & $-182.74(-228.55,-136.93)$ & $-353.25(-406.58,-299.92)$ & $<0.0001$ \\
\hline FVC & $-16.92(-19.86,-13.98)$ & 0 (ref) & $-104.36(-153.72,-55.01)$ & $-223.99(-278.26,-169.72)$ & $-434.46(-497.65,-371.28)$ & $<0.0001$ \\
\hline $\mathrm{FEV}_{1} / \mathrm{FVC}$ & $0.02(-0.03,0.07)$ & 0 (ref) & $0.28(-0.53,1.10)$ & $0.5 \mathrm{I}(-0.39, I .4 \mathrm{I})$ & $0.67(-0.38, I .7 I)$ & 0.1933 \\
\hline
\end{tabular}

Notes: *Models were adjusted for gender (male/female), age (continuous), city (Wuhan/Zhuhai), occupational hazard exposure (yes/no), drug status (yes/no), smoking status (smokers/nonsmokers), drinking status (drinkers/nondrinkers), regular physical activity (yes/no), cooking meals at home (yes/no), and family income ( $\geq 40,000 /<40,000 \mathrm{RMB} /$ year). ${ }^{\dagger}$ Models were adjusted for *models plus height, and weight. ${ }^{\ddagger}$ Models were adjusted for *models plus weight.

Abbreviations: BMI, Body mass index; WC, Waist circumference; WHR, Waist-to-hip ratio; WHtR, Waist-to-height ratio; FEV, forced expiratory volume in I s; FVC, forced vital capacity.

\section{Association Between CRP Concentration and Lung Function Alteration}

Table 4 presents the association between CRP concentration and lung function alteration. Results from the continuous analyses showed that each 1-unit increase in the log-transformed concentration of CRP was associated with a $58.25 \mathrm{~mL}$ and $71.64 \mathrm{~mL}$ decrease in $\mathrm{FEV}_{1}$ and FVC, respectively. In the categorical analyses, we found significantly monotonic $\mathrm{FEV}_{1}$ and $\mathrm{FVC}$ declines with increasing CRP. No significant association was found between plasma $\mathrm{CRP}$ and $\mathrm{FEV}_{1} / \mathrm{FVC}$. After performing stratified analyses, the findings among males, females, non-smokers were consistent with those from the primary analysis. While among smokers, no significant associations between CRP with $\mathrm{FEV}_{1}$ and $\mathrm{FVC}$ were observed anymore (Supplementary Figure 2).

\section{Role of Plasma CRP in the Associations Between Obesity Indices and Lung Function}

We assessed both joint effect and mediated effect of plasma CRP in the associations between abdominal obesity indices and lung function (Tables 5 and 6). Table 5 shows that
WHtR and plasma CRP had a joint effect on FVC $(P<0.05)$, other multiplicative interactions were not significant $(P>0.05)$. Table 6 shows the total effect, direct effect of abdominal obesity indices on $\mathrm{FEV}_{1}$ and $\mathrm{FVC}$ and mediation assessment on plasma CRP. We observed the mediated proportions of plasma CRP in associations of WC, WHR and WHtR with $\mathrm{FEV}_{1}$ were 7.96\%, 9.59\% and 5.76\%, respectively. The mediated proportions of plasma CRP in associations of WC and WHR with FVC were 8.33\%, 11.40\%, respectively. We did not find the mediated effect of plasma CRP in the associations between WHtR and FVC.

\section{Discussion}

In the present study, we observed that abdominal obesity indices (WC, WHR and WHtR) were negatively associated with $\mathrm{FEV}_{1}$ and $\mathrm{FVC}$ after adjusting for potential confounders in a general population in China. We also observed significantly positive associations between all obesity indices and plasma CRP and significantly negative associations between plasma CRP and lung function parameters ( $\mathrm{FEV}_{1}$ and $\left.\mathrm{FVC}\right)$. Plasma CRP may serve as a mediator in the associations of abdominal obesity indices (WC, WHR and WHtR) with decreased lung function. However, we did not find the significant association between BMI and lung function. The 
Table 3 Associations Between Obesity Indices and CRP ( $=3442)$

\begin{tabular}{|c|c|c|c|c|c|c|}
\hline \multirow{2}{*}{$\begin{array}{l}\text { Obesity } \\
\text { Indices }\end{array}$} & \multirow{2}{*}{$\begin{array}{l}\text { Estimated Changes mg/l ( } 95 \% \mathrm{CI}) \\
\text { by Continuous Obesity Indices }\end{array}$} & \multicolumn{4}{|c|}{ Estimated Changes in $\mathrm{mg} / \mathrm{l}(95 \% \mathrm{Cl})$ by Obesity Indices } & \multirow{2}{*}{$\begin{array}{l}P \text { value } \\
\text { for } \\
\text { Trend }\end{array}$} \\
\hline & & QI & Q2 & Q3 & Q4 & \\
\hline BMI* & $0.048(0.042,0.054)$ & $\begin{array}{l}\leq 21.63 \\
0 \text { (ref) }\end{array}$ & $\begin{array}{l}21.63-23.76 \\
0.124(0.068,0.180)\end{array}$ & $\begin{array}{l}23.76-26.09 \\
0.246(0.190,0.302)\end{array}$ & $\begin{array}{l}>26.09 \\
0.418(0.362,0.475)\end{array}$ & $<0.0001$ \\
\hline $\mathrm{wC}^{\dagger}$ & $0.005(0.002,0.007)$ & $\begin{array}{l}\leq 74.90 \\
0 \text { (ref) }\end{array}$ & $\begin{array}{l}74.90-81.60 \\
0.039(-0.021,0.099)\end{array}$ & $\begin{array}{l}81.60-88.20 \\
0.136(0.066,0.205)\end{array}$ & $\begin{array}{l}>88.20 \\
0.185(0.094,0.276)\end{array}$ & $<0.0001$ \\
\hline WHR*100 & $0.010(0.006,0.013)$ & $\begin{array}{l}\leq 82.06 \\
0 \text { (ref) }\end{array}$ & $\begin{array}{l}82.06-86.77 \\
0.104(0.046,0.153)\end{array}$ & $\begin{array}{l}86.77-91.54 \\
0.091(0.029,0.153)\end{array}$ & $\begin{array}{l}>91.54 \\
0.158(0.090,0.227)\end{array}$ & $<0.0001$ \\
\hline $\mathrm{WH} t \mathrm{R} * 100^{\ddagger}$ & $0.012(0.009,0.016)$ & $\begin{array}{l}\leq 47.17 \\
0 \text { (ref) }\end{array}$ & $\begin{array}{l}47.17-51.25 \\
0.080(0.021,0.137)\end{array}$ & $\begin{array}{l}51.25-55.52 \\
0.199(0.135,0.263)\end{array}$ & $\begin{array}{l}>55.52 \\
0.282(0.207,0.357)\end{array}$ & $<0.0001$ \\
\hline
\end{tabular}

Notes: *Models were adjusted for gender (male/female), age (continuous), city (Wuhan/Zhuhai), occupational hazard exposure (yes/no), drug status (yes/no), smoking status (smokers/nonsmokers), drinking status (drinkers/nondrinkers), regular physical activity (yes/no), cooking meals at home (yes/no), and family income ( $\geq 40,000 /<40,000 \mathrm{RMB} /$ year). ${ }^{\dagger}$ Models were adjusted for *models plus height (continuous), and weight (continuous). ${ }^{\ddagger}$ Models were adjusted for *models plus weight (continuous).

Abbreviations: CRP, C-reactive protein; BMI, Body mass index; WC, Waist circumference; WHR, Waist-to-hip ratio; WHtR, Waist-to-height ratio.

Table 4 Associations Between CRP and Lung Function Parameters ( $\mathrm{N}=3442)$

\begin{tabular}{|c|c|c|c|c|c|c|}
\hline \multirow{2}{*}{$\begin{array}{l}\text { Lung } \\
\text { Function } \\
\text { Parameters }\end{array}$} & \multirow{2}{*}{$\begin{array}{l}\text { Estimated Changes } \\
(\mathrm{mL})(95 \% \mathrm{Cl}) \text { by } \\
\text { Continuous CRP* }\end{array}$} & \multicolumn{4}{|c|}{ Estimated Changes in $\mathrm{mL}(95 \% \mathrm{Cl})$ by Quartile of Plasma CRP Level ${ }^{\dagger}$} & \multirow{2}{*}{$\begin{array}{l}P \text { value } \\
\text { for } \\
\text { Trend }\end{array}$} \\
\hline & & $\leq 0.226$ & $0.226-0.581$ & $0.58 I-1.38 I$ & $>1.38 \mathrm{I}$ & \\
\hline $\mathrm{FEV}_{\text {l }}$ & $-58.25(-81.74,-34.76)$ & 0 (ref) & $-38.12(-77.45,1.22)$ & $-42.26(-82.64,-1.87)$ & $-104.52(-145.88,-63.15)$ & $<0.0001$ \\
\hline FVC & $-71.64(-99.5 I,-43.78)$ & 0 (ref) & $-19.27(-65.95,27.41)$ & $-62.13(-110.06,-14.21)$ & $-113.91(-163.00,-64.82)$ & $<0.0001$ \\
\hline $\mathrm{FEV}_{\mathrm{l}} / \mathrm{FVC}$ & $0.20(-0.27,0.67)$ & 0 (ref) & $-0.80(-1.58,-0.01)$ & $0.31(-0.49,1.12)$ & $-0.20(-1.03,0.62)$ & 0.6920 \\
\hline
\end{tabular}

Notes: *Log-transformed CRP. †'Models were adjusted for gender (male/female), age (continuous), height (continuous), weight (continuous), city (Wuhan/Zhuhai), occupational hazard exposure (yes/no), drug status (yes/no), smoking status (smokers/nonsmokers), drinking status (drinkers/nondrinkers), regular physical activity (yes/ no), cooking meals at home (yes/no), and family income $(\geq 40,000 /<40,000 \mathrm{RMB} /$ year).

Abbreviations: CRP, C-reactive protein; $\mathrm{FEV}_{1}$, forced expiratory volume in I s; FVC, forced vital capacity.

results of the previous studies regarding the association between BMI and $\mathrm{FEV}_{1}$ or FVC were inconclusive. ${ }^{13,28-32}$ A cross-sectional study based on the British community did not find a linear association between $\mathrm{BMI}$ and $\mathrm{FEV}_{1}$ or $\mathrm{FVC}$ among 2633 adults, which was in accordance with our results. ${ }^{30}$ However, a cross-sectional study conducted in Mediterranean smokers found that BMI was inversely associated with lung function. ${ }^{31}$ Moreover, the National Health and Nutrition Examination Survey (NHANES III) reported an inverted U-shaped relationship between BMI and $\mathrm{FEV}_{1}$ and FVC. ${ }^{32}$ Such discrepancy may be due to differences in the ethnic group, heredity, and cigarette smoking.

Published studies ${ }^{14,15,28,29}$ have suggested that abdominal obesity was associated with impaired lung function, which was similar to our results. Although BMI is accepted worldwide as an important index of obesity, it fails to distinguish the fat mass from fat-free mass or to represent the pattern of fat distribution. With the measurement of
WC, WHR and WHtR, we were able to examine the association between the distribution of body fat and lung function, and the results suggested that abdominal obesity was strongly associated with $\mathrm{FEV}_{1}$ and $\mathrm{FVC}$ reductions. These results indicated that abdominal obesity indices may better reflect the effect of obesity on lung function.

Previous studies have shown that obesity was associated with systemic inflammation levels, while plasma CRP is the most commonly used marker of systemic inflammation. Among a general population in Taiwan area, obesity indices including BMI, WC and WHtR were significantly associated with elevated CRP levels in women. ${ }^{33}$ A study of 2589 individuals from Inner Mongolia in China found that WC was positively associated with the elevated risk of inflammation independently of BMI. ${ }^{34}$ Our results showed that both general (BMI) and abdominal obesity indices (WC, WHR and WHtR) were significantly and positively associated with plasma CRP in general adults. To exclude the potential 
Table 5 Joint Effect of Abdominal Obesity Indices and Plasma CRP on FEV, and FVC ( $\mathrm{N}=3442)$

\begin{tabular}{|c|c|c|}
\hline Parameter & $\begin{array}{l}\text { Estimated Changes } \\
(\mathrm{mL})(95 \% \mathrm{Cl}) \text { by } \\
\text { Continuous Obesity } \\
\text { Indices }\end{array}$ & $\begin{array}{l}\text { P for } \\
\text { Interaction }\end{array}$ \\
\hline \multicolumn{3}{|l|}{$W C^{*} \log C R P^{\dagger}$} \\
\hline $\mathrm{FEV}_{\mathrm{I}}$ & $-0.58(-2.31,1.16)$ & 0.5146 \\
\hline FVC & $-1.53(-3.59,0.53)$ & 0.1446 \\
\hline \multicolumn{3}{|l|}{$(\mathrm{WHR} * 100) * \log C R P^{\dagger}$} \\
\hline $\mathrm{FEV}_{1}$ & $-1.28(-4.57,2.02)$ & 0.4486 \\
\hline FVC & $-3.89(-7.80,0.02)$ & 0.0511 \\
\hline \multicolumn{3}{|l|}{$(\mathrm{WH} t \mathrm{R} * 100)$} \\
\hline \multicolumn{3}{|l|}{$* \log C R P^{\ddagger}$} \\
\hline $\mathrm{FEV}_{\mathrm{I}}$ & $-2.62(-5.48,0.23)$ & 0.0720 \\
\hline FVC & $-4.37(-7.76,-0.99)$ & 0.0114 \\
\hline
\end{tabular}

Notes: ${ }^{\dagger}$ Models were adjusted for gender (male/female), age (continuous), height (continuous), weight (continuous), city (Wuhan/Zhuhai), occupational hazard exposure (yes/no), drug status (yes/no), smoking status (smokers/nonsmokers), drinking status (drinkers/nondrinkers), regular physical activity (yes/no), cooking meals at home (yes/no), and family income $\left(\geq 40,000 /<40,000\right.$ RMB/year). ${ }^{\ddagger}$ Models were adjusted for tmodels without height (continuous).

Abbreviations: CRP, C-reactive protein; WC, Waist circumference; WHR, Waistto-hip ratio; WHtR, Waist-to-height ratio; $\mathrm{FEV}_{\mathrm{I}}$, forced expiratory volume in I s; FVC, forced vital capacity.

confounding effects of cigarette smoking, which can cause the increase of plasma CRP, ${ }^{35}$ we further separately evaluated the relationships between obesity indices and CRP levels among smokers and non-smokers. We found that the associations remained stable in both subgroups. These results suggested that the positive relationships between obesity indices and CRP occurred independently of cigarette smoking.

The inverse association between CRP and lung function has been reported in several studies. ${ }^{21-23,36}$ Aronson and his colleagues found inverse linear relationships between CRP concentrations and lung function in subjects without pulmonary disease and in never-smokers. ${ }^{22} \mathrm{~A}$ recent cross-sectional study showed that higher CRP concentration was associated with the lower lung volume. ${ }^{36}$ A 13-year follow-up study showed that lung function and CRP were inversely interrelated. $^{23}$ Similarly, we found inverse associations between plasma CRP and $\mathrm{FEV}_{1}$ and $\mathrm{FVC}$.

A cross-sectional study conducted in Korea reported the combined effects of body fat and CRP with pulmonary dysfunction. ${ }^{37}$ Similarly, we found a combined effect of WHtR and CRP on FVC. Furthermore, we performed a mediation analysis and innovatively found a mediating role for CRP in the association between abdominal obesity and decreased lung function. Numerous studies indicated that systemic inflammation occurred as a consequence of abdominal obesity, and recent insights suggested that CRP might play an important role in altered lung function. Abdominal adiposity led to distinct metabolic abnormalities such as increased levels of free fatty acid, ${ }^{38}$ which could trigger the release of CRP. ${ }^{17}$ On the other hand, the chronic systemic inflammation from obesity may enhance telomere shortening, which in turn leads to senescence of lung alveolar endothelial cells. ${ }^{39,40}$ Endothelial dysfunction induced by systemic inflammation ${ }^{41}$ may lead to pulmonary vascular filtration and lung tissue damage. These processes resulted in a comprehensive effect on pulmonary impairment. In the present study, plasma CRP mediated the associations of abdominal obesity indices with lung function reduction. It provides the basis for further mechanism study on this topic.

Some studies showed that gender modified the effect of obesity on lung function. ${ }^{13,42}$ In our analyses, the inverse

Table 6 Mediating Effects of Plasma CRP Level on Associations Between Abdominal Obesity Indices and FEV and FVC (N = 3442)

\begin{tabular}{|l|l|l|l|l|}
\hline Parameters & Total Effect & Mediated Effect & Direct Effect & Proportion Mediated (\%) \\
\hline FEV & & & & \\
WC & $-3.39(-5.16,-1.63)$ & $-0.27(-0.45,-0.09)$ & $-3.12(-4.88,-1.36)$ & 7.96 \\
WHR*100 & $-5.42(-8.04,-2.8 I)$ & $-0.52(-0.82,-0.22)$ & $-4.90(-7.52,-2.29)$ & 9.59 \\
WHtR*100 & $-14.23(-16.71,-11.75)$ & $-0.82(-1.19,-0.45)$ & $-13.41(-15.89,-10.92)$ & 5.76 \\
\hline FVC & & & & \\
WC & $-3.96(-6.06,-1.87)$ & $-0.34(-0.56,-0.12)$ & $-3.63(-5.72,-1.53)$ & 8.33 \\
WHR*100 & $-5.70(-8.81,-2.60)$ & $-0.65(-1.01,-0.28)$ & $-5.05(-8.16,-1.95)$ & 11.40 \\
WHtR*100 & $-11.46(-16.74,-6.18)$ & $1.65(-0.48,3.79)$ & $-13.12(-0.48,-9.38)$ & - \\
\hline
\end{tabular}

Notes: ${ }^{\dagger}$ Models were adjusted for gender (male/female), age (continuous), height (continuous), weight (continuous), city (Wuhan/Zhuhai), occupational hazard exposure (yes/no), drug status (yes/no), smoking status (smokers/nonsmokers), drinking status (drinkers/nondrinkers), regular physical activity (yes/no), cooking meals at home (yes/ no), and family income $\left(\geq 40,000 /<40,000 \mathrm{RMB} /\right.$ year). ${ }^{\ddagger}$ Models were adjusted for ${ }^{\dagger}$ models without height (continuous).

Abbreviations: CRP, C-reactive protein; WC, Waist circumference; WHR, Waist-to-hip ratio; WHtR, Waist-to-height ratio; FEV 1 , forced expiratory volume in I s; FVC, forced vital capacity. 
associations between abdominal obesity indices with $\mathrm{FEV}_{1}$ and FVC were significant in both men and women, though it tended to be weaker in women than in men. One possible explanation for the difference might be sex-based differences in lifestyle, hormonal system, body fat distribution, and pulmonary structure. To assess the impact of smoking on the relationships between obesity indices and lung function, we further evaluated the relationships in both smokers and non-smokers. Among non-smokers, we found inverse associations between abdominal obesity indices with lung function. However, such associations were no longer significant among cigarette smokers. Further subgroup analyses in smokers showed that smokers with abdominal obesity had a more evident obesity indices-associated lung function decline, compared with those without abdominal obesity. The possible reason might be that smoking covered the impact of obesity on lung function.

Our study has several strengths. First, the study was conducted among a relatively large population. Second, we measured individual plasma CRP and collected detailed personal life habit information data. Third, we identified a mediating role of systemic inflammation in the associations between abdominal obesity indices and lung function decline, which might contribute to the understanding of potential mechanisms. There are also some limitations in our study. First, we did not measure body fat directly. Second, this was a crosssectional study which did not reveal a causal relationship. Further longitudinal study would help to confirm the causal links among obesity indices, plasma CRP and lung function.

\section{Conclusions}

In this study, we found that abdominal obesity indices (WC, WHR and WHtR) were significantly and negatively associated with plasma CRP and $\mathrm{FEV}_{1}$ and FVC. Systemic inflammation may serve as a mediator in the associations of abdominal obesity indices (WC, WHR and WHtR) with decreased $\mathrm{FEV}_{1}$ and FVC.

\section{Abbreviations}

CRP, C-reactive protein; BMI, body mass index; WC, waist circumference; WHR, waist-to-hip ratio; WHtR, waist-to-height ratio; $\mathrm{FEV}_{1}$, forced expiratory volume in $1 \mathrm{~s}$; FVC, forced vital capacity; tumor $\mathrm{FEV}_{1} / \mathrm{FVC}$, ratio of $\mathrm{FEV}_{1}$ to $\mathrm{FVC} ; \mathrm{SD}$, standard deviation.

\section{Data Sharing Statement}

The datasets used and/or analysed during the current study are available from the corresponding author on reasonable request.

\section{Acknowledgments}

We sincerely thank all participants recruited in the study and the support from the study team.

\section{Author Contributions}

WC designed the Wuhan-Zhuhai cohort and funding obtaining. HH, BW, MZ and LC conceived and designed this study. All authors contributed to data analysis, drafting or revising the article, gave final approval of the version to be published, and agree to be accountable for all aspects of the work.

\section{Funding}

This study was supported by the National Natural Science Foundation of China (91843302 and 91543207) and National key research and development program of China (2016YFC1303903).

\section{Ethics Approval and Consent to Participate}

All participants in the study signed written informed consent. The study was approved by the Ethics and Human Subject Committee of Tongji Medical College, Huazhong University of Science and Technology.

\section{Disclosure}

The authors declare that they have no competing interests.

\section{References}

1. Abarca-Gómez L, Abdeen ZA, Hamid ZA, et al. Worldwide trends in body-mass index, underweight, overweight, and obesity from 1975 to 2016: a pooled analysis of 2416 population-based measurement studies in 128.9 million children, adolescents, and adults. Lancet. 2017;390 (10113):2627-2642.

2. Haslam DW, James WPT. Obesity. Lancet. 2005;366(9492):11 97-1209. doi:10.1016/S0140-6736(05)67483-1

3. Pabon MA, Ma KC, Choi AM. Autophagy and Obesity-Related Lung Disease. Am J Respir Cell Mol Biol. 2016;54(5):636-646. doi:10.1165/ rcmb.2016-0045PS

4. Shore SA, Johnston RA. Obesity and asthma. Pharmacol Ther. 2006;110(1):83-102. doi:10.1016/j.pharmthera.2005.10.002

5. Ortega FB, Lavie CJ, Blair SN. Obesity and Cardiovascular Disease. Circ Res. 2016;118(11):1752-1770. doi:10.1161/CIRCRESAHA.115. 306883

6. Lavie CJ, De Schutter A, Parto P, et al. Obesity and prevalence of cardiovascular diseases and prognosis-the obesity paradox updated. Prog Cardiovasc Dis. 2016;58(5):537-547. doi:10.1016/j.pcad.2016. 01.008

7. Fuster JJ, Ouchi N, Gokce N, Walsh K. Obesity-induced changes in adipose tissue microenvironment and their impact on cardiovascular disease. Circ Res. 2016;118(11):1786-1807. doi:10.1161/CIRCRES AHA. 115.306885

8. Andersson CX, Gustafson B, Hammarstedt A, Hedjazifar S, Smith U. Inflamed adipose tissue, insulin resistance and vascular injury. Diabetes Metab Res Rev. 2008;24(8):595-603. doi:10.1002/dmrr.v24:8 
9. Goossens GH. The role of adipose tissue dysfunction in the pathogenesis of obesity-related insulin resistance. Physiol Behav. 2008;94 (2):206-218. doi:10.1016/j.physbeh.2007.10.010

10. Kusminski CM, Bickel PE, Scherer PE. Targeting adipose tissue in the treatment of obesity-associated diabetes. Nat Rev Drug Discov. 2016;15(9):639-660.

11. Ix JH, Sharma K. Mechanisms linking obesity, chronic kidney disease, and fatty liver disease: the roles of fetuin-A, adiponectin, and AMPK. J Am Soc Nephrol. 2010;21(3):406-412. doi:10.1681/ ASN.2009080820

12. Fabbrini E, Sullivan S, Klein S. Obesity and nonalcoholic fatty liver disease: biochemical, metabolic, and clinical implications. Hepatology. 2010;51(2):679-689. doi:10.1002/hep.23280

13. Sorli-Aguilar M, Martin-Lujan F, Flores-Mateo G, et al. Adiposity markers and lung function in smokers: a cross-sectional study in a Mediterranean population. BMC Pulm Med. 2016;16(1):178. doi:10.1186/s12890-016-0341-y

14. Fenger RV, Gonzalez-Quintela A, Vidal C, et al. The longitudinal relationship of changes of adiposity to changes in pulmonary function and risk of asthma in a general adult population. BMC Pulm Med. 2014;14:208. doi:10.1186/1471-2466-14-208

15. Chen Y, Rennie D, Cormier YF, Dosman J. Waist circumference is associated with pulmonary function in normal-weight, overweight, and obese subjects. Am J Clin Nutr. 2007;85(1):35-39. doi:10.1093/ ajen/85.1.35

16. Saltiel AR, Olefsky JM. Inflammatory mechanisms linking obesity and metabolic disease. J Clin Invest. 2017;127(1):1-4. doi:10.1172/ JCI92035

17. Rocha VZ, Libby P. Obesity, inflammation, and atherosclerosis. Nat Rev Cardiol. 2009;6(6):399-409. doi:10.1038/nrcardio.2009.55

18. Frohlich M, Imhof A, Berg G, et al. Association between C-reactive protein and features of the metabolic syndrome - a population-based study. Diabetes Care. 2000;23(12):1835-1839. doi:10.2337/diacare. 23.12.1835

19. Devaraj S, Singh U, Jialal I. Human C-reactive protein and the metabolic syndrome. Curr Opin Lipidol. 2009;20(3):182-189. doi:10.1097/MOL.0b013e32832ac03e

20. Gould JM, Weiser JN. Expression of C-reactive protein in the human respiratory tract. Infect Immun. 2001;69(3):1747-1754. doi:10.1128/ IAI.69.3.1747-1754.2001

21. Rasmussen F, Mikkelsen D, Hancox RJ, et al. High-sensitive C-reactive protein is associated with reduced lung function in young adults. Eur Respir J. 2009;33(2):382-388. doi:10.1183/0903 1936.00040708

22. Aronson D, Roterman I, Yigla M, et al. Inverse association between pulmonary function and C-reactive protein in apparently healthy subjects. Am J Respir Crit Care Med. 2006;174(6):626-632. doi:10.1164/rccm.200602-243OC

23. Ahmadi-Abhari S, Kaptoge S, Luben RN, Wareham NJ, Khaw KT. Longitudinal association of C-reactive protein and lung function over 13 years: the EPIC-Norfolk study. Am J Epidemiol. 2014;179 (1):48-56. doi:10.1093/aje/kwt208

24. Song Y, Hou J, Huang X, et al. The Wuhan-Zhuhai (WHZH) cohort study of environmental air particulate matter and the pathogenesis of cardiopulmonary diseases: study design, methods and baseline characteristics of the cohort. BMC Public Health. 2014;14:994. doi:10. 1186/1471-2458-14-994

25. T.n.h.a.f.p.c.o.t.P.s.R.o. China, Criteria of weight for adults, WS/T. 428-2013(2013)
26. Miller MR, Hankinson J, Brusasco V, et al. Standardisation of spirometry. Eur Respir J. 2005;26(2):319-338. doi:10.1183/09031 936.05.00034805

27. VLaVT J. Mediation analysis allowing for exposure-mediator interactions - SAS and SPSS macros. Psychol Methods. 2013;18 (2):137-150. doi:10.1037/a0031034

28. Vatrella A, Calabrese C, Mattiello A, et al. Abdominal adiposity is an early marker of pulmonary function impairment: findings from a mediterranean Italian female cohort. Nutr Metab Cardiovasc Dis. 2016;26(7):643-648. doi:10.1016/j.numecd.2015.12.013

29. Pan J, Xu L, Lam TH, et al. Association of adiposity with pulmonary function in older Chinese: Guangzhou Biobank Cohort Study. Respir Med. 2017;132:102-108. doi:10.1016/j.rmed.2017.10.003

30. Fogarty AW, Lewis SA, McKeever TM, Britton J. The association of two different measures of body habitus with lung function: a population-based study. Respir Med. 2011;105(12):1896-1901. doi:10.1016/j.rmed.2011.07.024

31. Pistelli F, Bottai M, Carrozzi L, et al. Changes in obesity status and lung function decline in a general population sample. Respir Med. 2008;102(5):674-680. doi:10.1016/j.rmed.2007.12.022

32. Sin DD, Jones RL, Man SFP. Obesity is a risk factor for dyspnea but not for airflow obstruction. Arch Intern Med. 2002;162(13):1477. doi:10.1001/archinte.162.13.1477

33. Lin CC, Kardia SL, Li CI, et al. The relationship of high sensitivity C-reactive protein to percent body fat mass, body mass index, waist-to-hip ratio, and waist circumference in a Taiwanese population. BMC Public Health. 2010;10:579. doi:10.1186/14712458-10-579

34. Thompson AM, Zhang Y, Tong W, et al. Association of obesity and biomarkers of inflammation and endothelial dysfunction in adults in Inner Mongolia, China. Int $J$ Cardiol. 2011;150(3):247-252. doi:10.1016/j.ijcard.2010.04.011

35. Shiels MS, Katki HA, Freedman ND, et al. Cigarette smoking and variations in systemic immune and inflammation markers. J Natl Cancer Inst. 2014;106:11. doi:10.1093/jnci/dju294

36. Hancox RJ, Gray AR, Sears MR, Poulton R. Systemic inflammation and lung function: a longitudinal analysis. Respir Med. 2016; 111:54-59. doi:10.1016/j.rmed.2015.12.007

37. Jung DH, Shim JY, Ahn HY, Lee HR, Lee JH, Lee YJ. Relationship of body composition and C-reactive protein with pulmonary function. Respir Med. 2010;104(8):1197-1203. doi:10.1016/j.rmed.2010.02.014

38. Brooks GC, Blaha MJ, Blumenthal RS. Relation of C-reactive protein to abdominal adiposity. Am J Cardiol. 2010;106(1):56-61. doi:10.1016/j.amjcard.2010.02.017

39. MacNee W. Aging, inflammation, and emphysema. Am J Respir Crit Care Med. 2011;184(12):1327-1329. doi:10.1164/rccm.201110-1764ED

40. Tuder RM, Kern JA, Miller YE. Senescence in chronic obstructive pulmonary disease. Proc Am Thorac Soc. 2012;9(2):62-63. doi:10.15 13/pats.201201-012MS

41. Clapp BR, Hingorani AD, Kharbanda RK, et al. Inflammationinduced endothelial dysfunction involves reduced nitric oxide bioavailability and increased oxidant stress. Cardiovasc Res. 2004;64 (1):172-178. doi:10.1016/j.cardiores.2004.06.020

42. Steele RM, Finucane FM, Griffin SJ, Wareham NJ, Ekelund U. Obesity is associated with altered lung function independently of physical activity and fitness. Obesity (Silver Spring). 2009;17 (3):578-584. doi:10.1038/oby.2008.584 


\section{Publish your work in this journal}

Diabetes, Metabolic Syndrome and Obesity: Targets and Therapy is an international, peer-reviewed open-access journal committed to the rapid publication of the latest laboratory and clinical findings in the fields of diabetes, metabolic syndrome and obesity research. Original research, review, case reports, hypothesis formation, expert opinion and commentaries are all considered for publication. The manuscript management system is completely online and includes a very quick and fair peer-review system, which is all easy to use. Visit http://www.dovepress.com/testimonials.php to read real quotes from published authors.

Submit your manuscript here: https://www.dovepress.com/diabetes-metabolic-syndrome-and-obesity-targets-and-therapy-journal 